\title{
Quaderni
}

QUADERNI Communication, technologies, pouvoir

89 | Hiver 2015-2016

Penser l'avenir : le CESTA, un think tank atypique

\section{Maurice Mouillaud, Le discours et ses doubles. Sémiotique et politique}

Julien Longhi

\section{OpenEdition}

Édition électronique

URL : http://journals.openedition.org/quaderni/966

DOI : 10.4000/quaderni.966

ISSN : 2105-2956

Éditeur

Les éditions de la Maison des sciences de l'Homme

Édition imprimée

Date de publication : 5 janvier 2016

Pagination : 113-115

Référence électronique

Julien Longhi, « Maurice Mouillaud, Le discours et ses doubles. Sémiotique et politique », Quaderni [En

ligne], 89 | Hiver 2015-2016, mis en ligne le 05 janvier 2016, consulté le 25 septembre 2020. URL:

http://journals.openedition.org/quaderni/966 ; DOI : https://doi.org/10.4000/quaderni.966 


\section{Compte rendu}

\section{Le discours et ses doubles. Sémiotique et politique. \\ Maurice Mouillaud \\ PUL, Lyon, 2014}

par Julien Longhi

Université de Cergy-Pontoise

Cet ouvrage présente des textes de Maurice Mouillaud (professeur de psychologie sociale à l'Institut France Presse - Université Lyon 2, décédé en 2012), réunis par Jean-François Tétu et Geneviève Mouillaud-Fraisse : ce sont des écrits sur le discours politique (ceux sur les médias ont été exclus), dont une partie est un regroupement pour lequel la publication avait été prévue par l'auteur sous le titre Le Discours indicible. Études sur quelques polémiques $d u$ Parti communiste français au $X X^{e}$ siècle. Les autres textes inédits s'inscrivent dans un ensemble qui rejoindrait le projet plus vaste pensé par l'auteur sous le titre du présent ouvrage : Le discours et ses doubles (de l'indicible à l'invisible). Maurice Mouillaud avait en effet pensé explorer cette question du double des discours en plusieurs phases : pliages et dédoublements (le dédoublement du support matériel du texte) ; le double polémique (avec les conflits d'interprétation et de valeurs); le discours de contrebande (le discours confronté à une double contrainte) ; le discours indicible (l'énonciateur est soumis à des injonctions contradictoires); et le Monument invisible (interrogation sur la double contrainte dans le discours argumentatif et en art).

La première partie, intitulée Le discours indicible, rassemble des «Études sur quelques polémiques du Parti communiste français au $\mathrm{XX}^{\mathrm{e}}$ siècle ». Le Parti communiste est présenté comme un pivot dans les recherches de l'auteur, et constitue en effet un véritable observatoire du discours et de ses doubles : « problème de la contraception et de l'avortement; position du parti par rapport aux femmes; relation aux critiques et aux dissidents [...] ; rapport à l'Union soviétique » (p. 19). Le chapitre sur la loi, les femmes et l'avorte- 
ment, est tout à fait éclairant pour étayer le propos de Maurice Mouillaud sur le discours et ses doubles : en particulier, l'étude des différentes modalités des discours de la loi, du malthusianisme et du planning (synthétisée dans le tableau page 65) permet de relier les normes prescriptives du discours (qui articulent le devoir et le faire) aux formes linguistiques produites : les femmes sont un enjeu du discours communiste qui souhaite leur restituer « la maternité que le capitalisme voudrait leur dérober » (p. 89).

Les chapitres suivants mettent à profit le cadre théorique pour analyser les mots « liquidateur » et « rénovateur » (qui renvoient aux membres du Parti qui contestent la ligne), ainsi que le procès de Leningrad (1970-1971, avec le double discours de l'Humanité sur la condamnation puis la réhabilitation de « deux Juifs accusés de piraterie aérienne ») : dans ce second exemple, l'auteur montre que la sémantique migre de la langue de la police à celle de la justice ; il explicite surtout ce discours au regard de l'antisémitisme indicible, " enfui ou raturé, non dit ou contredit » (p. 149) : "faute d'être admis dans le corps du texte, l'antisémitisme le hante » (p. 150).

Dans la seconde partie, Le discours et son double. La polémique et les polémiques, l'auteur tente de définir « l'apolémique » : c'est « une relation qui caractérise le rapport entre deux mondes » (p. 167). Pour cela, il définit la polémique : «la polémicité est ainsi comprise entre deux bornes : des récits intouchables lorsque le mythe est effervescence, le récit de l'Holocauste par exemple, et des mythes devenus froids comme celui de la religion et du pouvoir absolu dans la France du XVIII siècle » (p. 174). Il s'appuie sur les travaux de Goffman, et reprend la métaphore théâtrale, pour affirmer que « dans le même temps, captivant et distancié, alors la vigilance polémique ne dort jamais que d'un oil »: «loin de se réduire au dérèglement, la polémique, ce sont les lignes de faille, de plus ou moins grande ampleur, qui creusent le social et le politique (et pas seulement eux), elles en sont l'animation ou la réanimation permanente, ce sans quoi le penser tomberait dans la stupeur » (p. 188). Les chapitres suivants traitent d'exemples de polémiques que faute de place je ne pourrai décrire ici (Mario Vargas Llosa et Régis Debray, Joseph Reinach et Maurice Barrès, puis Marc Antoine, Léo Strauss, et Derrida lecteur de Foucault).

L'ouvrage se termine par un très intéressant chapitre intitulé « La fabrique du cadre » : il s'appuie sur la description d'un lexique (scène, format, passages) 
et décrit les « effets de limite», dans une approche relativement proche de la Gestalttheorie. Cette définition conclusive aura une portée dans une pluralité de champs et de domaines, et synthétise bien le dynamisme et la souplesse des analyses de Maurice Mouillaud : "le mot fabrique pouvait s'autoriser la fabrication décrite par Goffman, bien que celui-ci se fût intéressé à la sous-traitance du terme plutôt qu'à la fabrication du cadre même. Ce serait donc "La fabrique du cadre »; du moins, jusqu'à ce que cette négociation finisse par se désigner pour ce qu'elle avait été depuis le commencement, une longue série de variations » (p. 302).

On l'aura compris, la lecture de ces textes de Maurice Mouillaud est d'une grande richesse, à la fois pour l'éclairage sur des sujets sociaux ou politiques, mais aussi pour la finesse de la méthode et la qualité des analyses. Ces travaux résonnent également avec certaines recherches plus récentes, telles que celles de N. Chomsky par exemple (De la propagande, entretiens avec David Barsamian) sur la problématique de la fabrique du consentement. Il semble également que cet auteur, peut-être plus connu par les politistes que par les linguistes, est une référence précieuse pour (re)penser la théorie du discours à partir de corpus complexes, qui entremêlent plusieurs voix, normes, enjeux, et donnent à voir une complexité qu'il est nécessaire de traduire en propositions théoriques, ce dont rend parfaitement compte l'agencement des textes proposés dans ce volume. 
